\title{
Explicating development of personal professional theories from higher vocational education to beginning a professional career through computer-supported drawing of concept maps
}

Citation for published version (APA):

van den Bogaart, A. C. M., Hummel, H. G. K., \& Kirschner, P. A. (2018). Explicating development of personal professional theories from higher vocational education to beginning a professional career through computersupported drawing of concept maps. Professional Development in Education, 44(2), 287-301. https://doi.org/10.1080/19415257.2017.1288652

DOI:

10.1080/19415257.2017.1288652

Document status and date:

Published: 01/01/2018

Document Version:

Peer reviewed version

Document license:

CC BY-NC-ND

Please check the document version of this publication:

- A submitted manuscript is the version of the article upon submission and before peer-review. There can be important differences between the submitted version and the official published version of record. People interested in the research are advised to contact the author for the final version of the publication, or visit the DOI to the publisher's website.

- The final author version and the galley proof are versions of the publication after peer review.

- The final published version features the final layout of the paper including the volume, issue and page numbers.

Link to publication

General rights

Copyright and moral rights for the publications made accessible in the public portal are retained by the authors and/or other copyright owners and it is a condition of accessing publications that users recognise and abide by the legal requirements associated with these rights.

- Users may download and print one copy of any publication from the public portal for the purpose of private study or research.

- You may not further distribute the material or use it for any profit-making activity or commercial gain

- You may freely distribute the URL identifying the publication in the public portal.

If the publication is distributed under the terms of Article 25fa of the Dutch Copyright Act, indicated by the "Taverne" license above, please follow below link for the End User Agreement:

https://www.ou.nl/taverne-agreement

Take down policy

If you believe that this document breaches copyright please contact us at: pure-support@ou.nl

providing details and we will investigate your claim.

Downloaded from https://research.ou.nl/ on date: 26 Apr. 2023 
Development of Personal Professional Theories:

from Higher Vocational Education into Beginnings of Professional Careers

\author{
Antoine C. M. van den Bogaart ${ }^{1}$, \\ Hans G.K. Hummel ${ }^{2} \&$ Paul A. Kirschner ${ }^{2}$ \\ ${ }^{1}$ NHL University of Applied Science, The Netherlands \\ ${ }^{2}$ Open University of the Netherlands
}

\begin{abstract}
Author Note
Correspondence concerning this article can be addressed to Antoine C. M. van den Bogaart, NHL University of Applied Science, Rengerslaan 10, 8917 DD Leeuwarden, The Netherlands, E-mail: a.c.m.van.den.bogaart@nhl.nl
\end{abstract}

Key words: personal professional theories, expertise development, teaching, accountancy. 


\begin{abstract}
This article explores the problem how Personal Professional Theories (PPTs) develop. PPT development of nine junior accountants and nine novice teachers was monitored by repeated measurements over a period of one-and-a-half year, from the last year of vocational education until the second year of their professional careers. Concept maps were used at three moments to test hypotheses derived from theories on expertise development. It could be concluded that on average PPTs became more complex, the PPTs of teachers also became richer, but the generality of PPTs did not significantly increase. (Dis)appearance of concepts and changes in their importance were observed and appeared dependent on the professional environment of the participants. The findings indicate that PPT development is an important manifestation of expertise development and the concept map method appears suited to reveal it.
\end{abstract}




\section{Introduction}

A personal professional theory (PPT) is a personal knowledge base stored in the longterm memory of a practitioner. It contains the semantic, procedural and practical knowledge, together with norms, values, goals and self-knowledge, needed to do one's job as one sees fit, assimilated and accommodated into mental schemata (Schaap, De Bruijn, Van der Schaaf, \& Kirschner, 2009; Schaap, 2011).

The importance of the construct PPT originates in theories on expertise development. According to van der Heijden (1998) these theories have undergone three paradigm shifts: (1) from power based to knowledge based, (2) from focussing on forming powerful routines to emphasizing flexibility, and (3) from innate to resulting from extended and deliberate training and practice. The first shift claims that understanding expertise is not "the identification of a few powerful techniques, but rather the question how to represent large amounts of knowledge that permits their effective use and interaction" (Goldstein and Papert (1977) as cited by van der Heijden, 1998, p. 32). This is where a PPT fits in, as it serves its owner as an individual frame of reference for professional actions (Schaap et al., 2009). It is also relevant in regard to the second and third paradigm shifts, as flexibility and deliberate practice require self-regulation and thus personal goals and self-knowledge (Bandura, 1991). That is why a PPT functions as a frame of reference for the acquisition and interpretation of new professional knowledge and experiences over time within the domain of expertise and when making a transfer across different domains (Schaap et al., 2009).

The construction of one's PPT starts in vocational education or at university and continues during his/hers professional career (Schaap, de Bruijn, \& van der Schaaf, 2007). Although research on expertise development has a long tradition in 
cognitive psychology (Chi, Feltovich, \& Glaser, 1981; de Groot, 1965; Vaatstra, 1996), it is not really clear how PPTs develop (Schaap, van der Schaaf, \& de Bruijn, 2011). Research on the development of PPTs has to answer several interrelated questions such as "What are the changes over time in PPTs?" and "What causes or influences these changes?" Both questions are important because when we know how PPTs develop, ways can be designed, developed and tested to stimulate their development. This study focuses primarily on the first question: "What are the changes over time in PPTs?" The second question is addressed in so far that based on literature, a specific period was chosen in which PPT development could be expected. It is therefore reasonable to assume that characteristics of this period will contribute to the development.

To answer the first question, a method has to be available to represent PPTs since they are mental constructs and not observable directly. Van den Bogaart, Schaap, Hummel, and Kirschner (submitted b) developed and validated a method to represent PPTs by means of replenished, annotated, open concept maps. The production of such representations consists of three steps: 1) the construction of an open annotated concept map, 2) a semi-structured interview on the concept map, and 3) insertion of the relevant data from the interview in the concept map. The nodes in the maps denote concepts, the main semantic elements of professional theories. The links denote relations between concepts. Relations clarify the meaning of concepts, as do annotations. Annotations offer also the possibility to attach to concepts procedural knowledge, goals, norms and values in which these concepts are used (van den Bogaart et al., submitted b). This way the representations offer both a global overview of PPTs and the possibility to highlight details. 
However, this method of representing PPTs has some limitations. First, the representations offer a limited amount of information on PPTs. The construction of a concept map takes no longer than two hours, after that fatigue occurs. This restricts the number of concepts, relations and annotations. As a consequence, the representations may lack detailed information on the structure of chunks of possibly compiled or encapsulated knowledge (Schmidt \& Boshuizen, 1993). In addition, the concept map provides a momentary, static, and subjective image of a PPT. How its content is actually used by its owner remains hidden. For instance it remains unclear whether a primary concept in a map really is important for its owner in the sense that it is often used (Buitink, 1998). With these limitations in mind the conclusion can be drawn that concept maps might be suited to study the development of PPTs.

The foregoing led to the aim of the study: to research the development of PPTs by means of their representations by replenished, open, annotated concept maps. To achieve this aim, it is discussed in the theoretical section: (1) what are possibly relevant PPT development indicators connected to changes in concept maps (and what hypotheses can be formulated related to them), and (2) in what period development might be observed to test the hypotheses. The theoretical analysis in the next section will lead to four hypotheses and is illustrated with examples from two domains: accountancy and teaching English as a foreign language. The domains are chosen because they are opposites of each other from a certain point of view: accountancy is a highly protocollised domain contrary to the less structured teaching domain with its twofold knowledge base (subject- and teaching-knowledge) (van den Bogaart et al., submitted b).

\section{Theoretical Background}




\section{The derivation of hypotheses concerning PPT development indicators}

The derivation consisted of three steps.

The first step was to characterise aspects of professional expertise development which might be relevant in the development of PPTs. According to van der Heijden (1998) expertise development can be characterised, domain independently, by changes in five dimensions which can be found in more recent literature too: (1) professional knowledge, the theoretical and practical knowledge (Schaap, et al., 2011) necessary to execute professional tasks, (2) meta-knowledge, which is important in goal setting, monitoring task execution and self-regulating (Kereluik, Mishra, Fahnoe, \& Terry, 2013), (3) skills, narrowly connected to procedural knowledge (Baartman \& de Bruijn, 2011), (4) flexibility, coming from the need to adapt and innovate (Piore, 2002), and (5) social recognition, both by colleagues in the same profession and by the purchasers of services the practitioner provides (Dalton, Thompson, \& Price, 1977; Moline, 1986). In these five dimensions the cognitive, social and motivational aspects of expertise are combined. For instance, "motivation to monitor one's own achievements is crucial for the enlargement of one's knowledge and skills and for the acquisition of flexible expertise" (van der Heijden, 1998, p. 61). The higher someone is rated along the five dimensions, the higher the probability is of excellent performance and of being recognised as an expert.

The second step entailed the formulation of suppositions on the development of PPTs in the five dimensions. An overview of the suppositions is given in Table 1. 


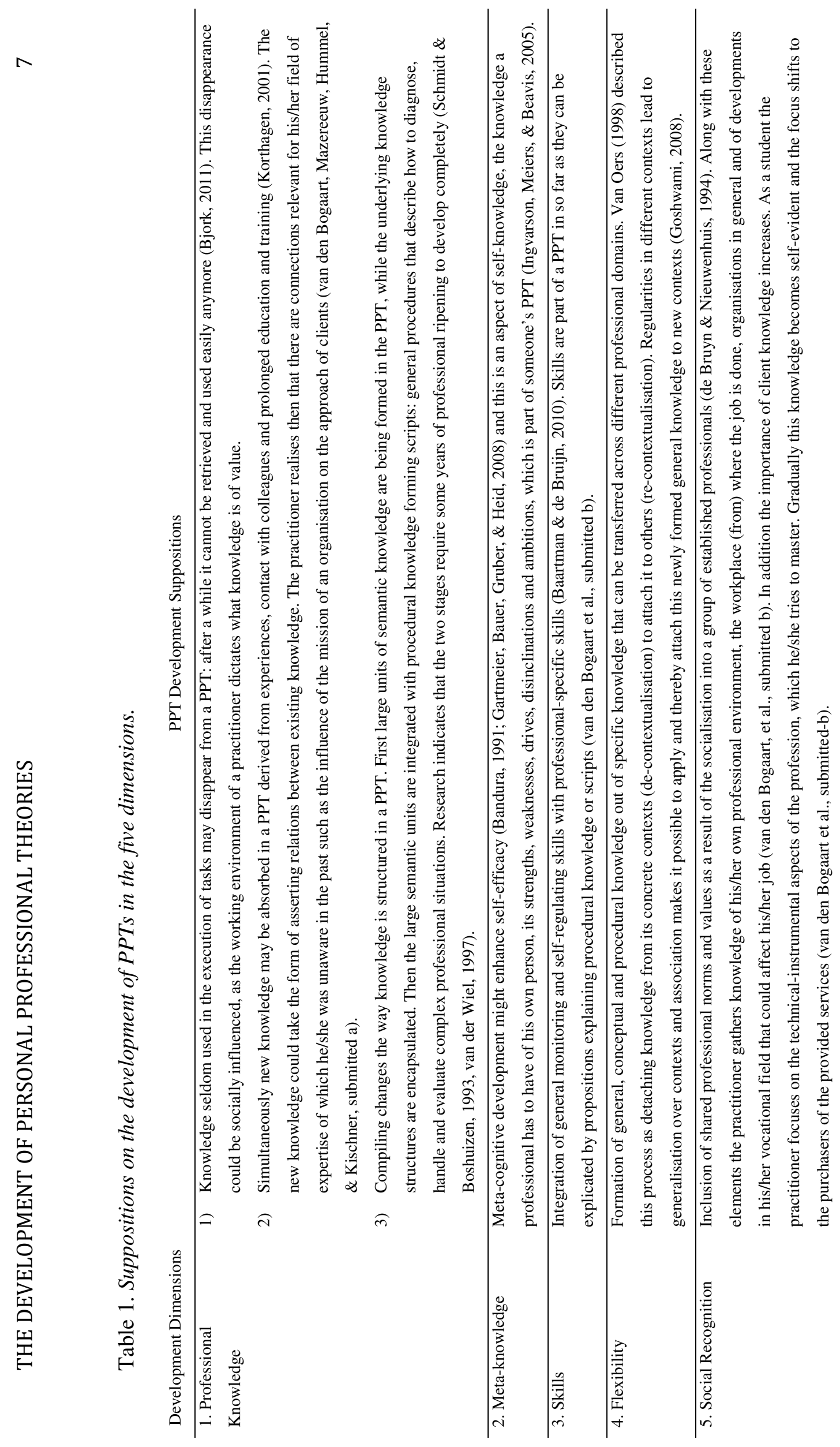


In the third step these suppositions were transformed into four hypotheses using suitable indicators.

The first hypothesis is about the complexity of PPT concept maps. This quality can be validly operationalized as the degree the content of a concept map is interconnected by relations (Sweller, 2006; van den Bogaart, Bilderbeek, Schaap, Hummel, \& Kirschner, 2016). The degree can be calculated as a percentage. By definition a concept map is $100 \%$ complex if all its concepts are connected with at least three other concepts. It can be expected from the description of the knowledge dimension that at least in the beginning of a professional career the concept map of a PPT might become more complex. The reason for this is that the practitioner becomes aware of new connections and influences in his/her field of expertise. As argued in Table 1, complexity might decrease because knowledge (including relations) disappears from a representation because it is seldom used or becomes encapsulated. However in both cases the effects on complexity might be weak. In case of knowledge seldom used this might be the case, because it is likely that the disappearing knowledge elements are not connected strongly in the concept map, otherwise they could not disappear so easily. In case of the encapsulation of knowledge the effect might be weak in the beginning of a professional career.

The second hypothesis is about the richness of PPT concept maps. This quality has been operationalized as a combination of (1) the level of uniformity with which the content of these maps is distributed over six domains of professional knowledge: vocational field, organisations, professional environment, target groups, technical-instrumental knowledge and self-knowledge and development, and (2) the degree to which each domain is present to a sufficient extent. Again the level of 
richness can be calculated as a percentage, using a formula derived from ecology to express species diversity in an ecosystem (van den Bogaart et al., 2016). From the description of the two knowledge dimensions and the social dimension in Table 1 it can be expected that PPT concept maps become richer. As self-knowledge, organisational knowledge and domain knowledge increase, technical-instrumental knowledge becomes self-evident and thus less prominent, while the importance of target-group knowledge rises, the content of PPT concept maps becomes more uniformly distributed over the six domains.

The third hypothesis about PPT development uses a new indicator to measure changes in the level of generality of concepts in PPT concept maps that will be operationalized in the method section. It is not clear from the suppositions in Table 1 how the level of generality might develop, as there are several opposite tendencies that may influence it. On the one hand (important/primary) concepts might become more general in time, due to compiling processes and the generation of flexible applicable knowledge. On the other hand the appearance of new concepts might diminish the average level of generality because they might be of a particular nature as they refer to individual experiences. As it is not clear whether there is a dominant tendency in a given stage of a professional career, the third hypothesis connected with this indicator simply states that the average level of generality of concepts in a PPTs concept map changes.

Finally, the description of PPT development in Table 1 implies that it might be possible that professional knowledge disappears from PPTs because it is seldom used in practice or that its content changes because the PPT owner changed some of his/her professional views possibly due to influences of his/her professional environment, new experiences and/or new knowledge he/she acquires (Clarce \& Hollingsworth, 
2002). This is the fourth hypothesis. The disappearance of professional knowledge from a PPT could be detectable from concept maps as the disappearance of concepts. View changes could become visible as changes in a map's structure, such as a change in the order of concepts. If a primary concept develops into a sub-concept, this could be interpreted as an indication that the concept becomes less important in a PPT (Huyts, de Bruijn, \& Schaap, 2011).

\section{From Higher Vocational Education into the beginning of a professional career}

There is evidence that PPTs develop slowly. Schaap et al. (2011) followed students of senior secondary vocational education during 40 weeks without measuring significant changes in their PPTs. In another study reported in Schaap's dissertation (2011), an effort was undertaken to stimulate the development of PPTs of students by means of discussions with their teachers on critical situations. Again no substantial effects were measured. The slow development could be explained by the fact that the content of a PPT is stored in long-term memory, which takes time (Sweller, 2006). In addition, it could also be that the nature of the curriculum does not provide a sufficiently strong stimulus for the transformation processes described in the preceding section (Schaap, 2011; Schmidt \& Boshuizen, 1993).

A powerful source for PPT development comes from the confrontation with practice. For vocational students this starts with their periods of workplace learning (i.e., apprenticeships) (Eraut, 2009). Although the transfer of knowledge between school and workplace cannot be taken for granted, learning effects seem to be significant (Schaap, Baartman, \& de Bruijn, 2012). There is also evidence that PPTs develop during the first years of a career. After completing vocational education and thereby closing the pre-professional phase, one enters what is called the induction phase (Vonk, 1995). Both for novice teachers and accountants research indicates 
strong effects on professional and personal development in this period culminating ultimately in a decision to stay (retention) or to leave the profession (attrition) (Chan, Monroe, Ng, \& Tan, 2008; Helms-Lorentz \& Maulana, 2015). The first (two) years of the induction period are called the threshold-phase (Vonk, 1995). From the perspective of PPT development this phase is particularly interesting because here the perspective of the novice on the profession changes. The beginning teacher struggles to accept his/her role and tries to cope with the new responsibilities. Identification with pupils comes to an end, as well as the perspective on good teaching based on experiences as a learner (Vonk, 1995). Junior accountants have to accept their role as an intermediate between client and society. Their technical-analytical skills have to be put at the service of business awareness, soft skills and knowledge of the 'real world' (Gracia, 2010; Kavanaugh \& Drennan, 2008).

\section{Research questions}

The aforementioned led to four specific questions regarding the transition through the threshold-phase:

(1) Do concept maps of PPTs get more complex? (2) Do PPT concept maps become richer? (3) Does the average level of generality of their concepts change? (4) Do PPTs' concept maps manifest (dis)appearance of concepts or changes in their order? The choice for two domains (teaching and accountancy) where these questions will be answered, makes it possible to compare developments in both domains.

\section{Method}

A small group study with a repeated measurements design was conducted with a group of nine junior accountants and a group of nine novice teachers. Both groups were followed from April 2014 till October 2015. In this period each participants 
constructed and discussed three annotated concept maps of his/her PPT (i.e., April 2014, December 2014, October 2015). More frequent mapping did not seem necessary considering the slow development of PPTs. Analysis of the concept maps with respect to complexity, richness, generality, the (dis)appearance of concepts and to changes in structure led to the answers on the four research questions.

\section{Participants}

At the start of the study (April 2014) all participants were students of accountancy or teachers in training, in their last semester of their fourth and last year at a regional university for higher vocational education in the Netherlands. Although the students differed in the number of credits they had yet to obtain to graduate, in principle each would graduate that summer. The study started with 23 students accountancy and 16 student teachers who had a foreign language as their subject, but when it came to the second measurement in December 2014, only 9 accountancy participants that had graduated remained: 3 male, 6 female, $M_{\text {age }}=22$ years, $S D=1$ year, and also 9 novice teachers that had recently graduated: 4 male, 5 female, $M_{\text {age }}=23$ years, $S D=2$ years. The rest had not finished their education yet, was not working in the profession they were trained for, or could not participate for personal reasons. These same 18 participants also participated in the third and last measurement in October 2015. One participant changed jobs just before the last measurement. Three participants changed jobs immediately after the measurements were completed.

\section{Instruments}

The construction of the concept maps of the PPTs was executed in two steps. First, each participant constructed a map supported by a module of the dedicated computer program BrainWeaver® (van den Bogaart et al., 2016). The module allows drawing open concept maps with focus "As an accountant/teacher I have professional 
knowledge of and judgements on ..". The concepts and relations in the maps can be explained by subjoining examples or clarifications. Then, to generate as much information on the PPTs as possible, each map was discussed in a semi-structured interview with its owner and the information from the interview was used to update the map (van den Bogaart et al., submitted b).

In the second and third measurement the questions in the semi-structured interview also referred to the differences with the preceding concept map and to the learning process the interviewee had gone through since that last interview. The degrees of complexity and richness of the concept maps, replenished with the information from the interviews, were expressed as percentages and calculated by trained assessors supported by the assessment module of BrainWeaver® (van den Bogaart et al., 2016).

To compare two replenished concept maps with regard to their level of generality, an adaptation of a method introduced in van den Bogaart et al. (submitted a) was used. First both maps were pruned. This means that all relations between concepts expressing that one concept is a part or an example of the other as well as exemplary concepts are deleted from both maps. That a concept is a part or example of another can be derived from relations such as 'consists' or 'contains'. For example, the concept "annual account" contains the concept "profit and loss account". Subsequently, exemplary concepts ("profit and loss account") and their annotations are inserted as annotations into the related, comprising concepts ("annual account"). Then each pruned map was awarded with one point for every concept that is a generalisation of one or more concepts in the other map. By definition, a concept is a generalisation of another concept if and only if the extension of the second concept is part of the extension of the first. In this definition the extension of a concept is the set 
of all knowledge-elements belonging to the concept. For example the concept "classroom management" is a generalisation of the concepts "keeping order in the classroom" and "keeping track of time" (van den Bogaart et al., submitted a). Deciding if a concept is a generalisation of another proved reliable as tests showed that trained assessors agreed on the awarding with grades (van den Bogaart et al., submitted a). Finally, the map with most points was considered more general as the other.

Comparing all three maps of a participant pairwise made it possible to rank them according to the level of generality. The most general map got ranking one, the second got two and the least general map got ranking three. (If the rankings of two maps were the same, the map with the highest number of points for generality 'won'.) Analysis

To analyse the concept maps in relation to the first three research questions, the complexity and richness of each map was determined, as well as its generality ranking. This led to three $H_{0}$-hypotheses in each domain, assuming that the complexity, richness and generality of the concept maps would stay the same. The hypotheses on complexity and richness were tested by means of one-way repeated measures ANOVA's. The hypothesis on generality was tested by means of a Friedman two-way ANOVA as the variable ranking number is of ordinal type.

To answer the fourth research question, the first and second concept maps were searched for concepts that did not appear in respectively the second and third concept map and for changing opinions. Such changes were detected on the basis of two indicators: changing of a concept from primary to non-primary or the other way around, and conflicting annotations in successive concept maps.

\section{Procedure}


In January 2014 the fourth year students Accountancy and Teaching with a foreign language as their subject were told the goals and design of the study and were invited to participate. Six students could not participate due to personal reasons. All participating students received a thorough explanation of what a PPT was and how a representation of it could be constructed by means of a concept map and an interview. In the first measurement (April 2014), 39 concept maps were constructed and 39 interviews were held. As explained, these numbers reduced to 18 in the second (December 2014) and third measurement (October 2015). The construction time of the concept maps was between 45 and 75 minutes and did not differ between the three measurements. The day after completing the concept map in BrainWeaver participants received a PDF of their map and annotations. Within a week, a follow-up interview was held to discuss the concept map. In the second and third interviews, the differences with the preceding map and the learning experiences since the preceding interview were also discussed in the interviews. The interviews took between 30 and 45 minutes and were carried out via telephone. (Two, final interviews were held face to face, because the interviewees wanted to say good bye. The questions in these two interviews were the same as in the telephone interviews and interaction was minimized: the interviewee looked at his/her concept map and answered the questions.) All participants expressed that participation in the study was sometimes difficult due to heavy workload, but was enjoyable too and provided them with a valuable opportunity to reflect on the development of their views on the profession. In each domain, two staff members of the university who already assisted in earlier studies (van den Bogaart et al., 2016; van den Bogaart et al., submitted b; van den Bogaart et al., submitted a) cooperated in the determination of the values of the 
three indicators. Changes in the order of concepts accompanied with changes in label (i.e., "social skills" changing into "soft skills") were discussed with the assessors too.

\section{Results}

Table 2 displays the mean values and standard deviations for complexity, richness and the mean generality ranking of the three replenished concept maps in each domain.

Table 2. The development of complexity, richness and generality

\begin{tabular}{llccc}
\hline & & First concept map & Second concept map & Third concept map \\
& & $M(S D)$ & $M(S D)$ & $M(S D)$ \\
\hline \multirow{3}{*}{ Accountants } & Complexity & $44(13)$ & $44(14)$ & $69(10)$ \\
\cline { 2 - 5 } & Richness & $56(16)$ & $65(9)$ & $70(12)$ \\
\cline { 2 - 5 } Teachers & Mean Generality Rank & 1.8 & 2.2 & 2.0 \\
\hline & Complexity & $44(17)$ & $58(15)$ & $73(9)$ \\
\cline { 2 - 5 } & Richness & $54(8)$ & $67(18)$ & 1.6 \\
\cline { 2 - 5 } & Mean Generality Rank & 2.3 & 2.1 & $76)$ \\
\hline
\end{tabular}

Shapiro-Wilk statistics indicated that in both domains the normality assumption was supported for complexity and richness. The largest $F_{\max }$ was 4.5, demonstrating homogeneity of variances in all four cases, and Mauchly's test indicated sphericity. The ANOVA results show that in both domains the complexity of the concept maps changed in time with substantial effect size:

$F_{\text {accountants }}(2,16)=14,23, p<.001, \eta_{p}^{2}=.64$ and $F_{\text {teachers }}(2,16)=11.55, p<.001$, $\eta_{p}^{2}=.59$. Pairwise comparisons revealed that the maps in third measurement were significantly more complex then the maps in the first two measurements. For richness, we see a similar increase for both groups, but only the results of the teachers were significant: $F_{\text {accountants }}(2,16)=3,23, p=.066$, partial $\eta^{2}=.29$ and $F_{\text {teachers }}(2,16)=5.61, p=.014, \eta_{p}^{2}=.41$. Additional information on richness can be found in the distribution over the six domains of knowledge in the concept maps, as is shown in Table 3. 
Finally, the Friedman two way ANOVA revealed no significant differences between the levels of generality of the concept maps in the three measurements, respectively: $\chi_{F, \text { accountants }}^{2}=.69, d f=2, p=.7$ and $\chi_{F, \text { teachers }}^{2}=4.0, d f=2$, $p=.14$.

Table 3. The relative frequencies of the domains of knowledge

\begin{tabular}{|c|c|c|c|c|c|c|}
\hline & \multicolumn{3}{|c|}{ Accountants } & \multicolumn{3}{|c|}{ Teachers } \\
\hline & $\begin{array}{c}\text { First } \\
M(S D)\end{array}$ & $\begin{array}{l}\text { Second } \\
M(S D)\end{array}$ & $\begin{array}{c}\text { Third } \\
M(S D)\end{array}$ & $\begin{array}{c}\text { First } \\
M(S D)\end{array}$ & $\begin{array}{l}\text { Second } \\
M(S D)\end{array}$ & $\begin{array}{c}\text { Third } \\
M(S D)\end{array}$ \\
\hline Vocational Field Knowledge & $12(8)$ & $11(8)$ & $8(6)$ & $4(4)$ & $5(5)$ & $7(4)$ \\
\hline Organisations & $4(5)$ & $9(12)$ & $4(4)$ & $9(7)$ & $12(10)$ & $11(6)$ \\
\hline Professional environment & $2(2)$ & $11(4)$ & $14(7)$ & $1(1)$ & $9(5)$ & $9(6)$ \\
\hline Target group & $9(7)$ & $12(10)$ & $9(5)$ & $12(8)$ & $12(5)$ & $20(6)$ \\
\hline Technical-instrumental & $58(17)$ & $43(17)$ & $47(14)$ & $62(12)$ & $48(19)$ & $38(11)$ \\
\hline Self-knowledge & $12(8)$ & $15(9)$ & $18(3)$ & $13(10)$ & $15(9)$ & $15(7)$ \\
\hline
\end{tabular}

Four typical replenished, pruned concept maps are depicted in Figures 1, 2, 3 and 4. Two maps (Figures 1 and 2) were constructed by a participating (student) accountant in respectively the first and the third measurement. The other two (Figures 3 and 4) were constructed in the same measurements by a participating (student) teacher. For the sake of clarity only the annotations of one concept are shown. In regard to the fourth and last hypothesis, Table 4 shows the numbers of primary concepts and for the second and third measurement the numbers of lower order concepts that were primary in the preceding concept map. The primary concepts in the second and third concept maps are itemized according to their status in the preceding map. All numbers were calculated from pruned maps. To keep Table 4 concise, two numbers were not included but they can be calculated from the data in the table: the total number of primary concepts in the second and third measurement $((a)+(b)+(c))$, and the number of disappearing concepts in these measurements: the number of primary concepts in the former measurement minus (a) and (d). 


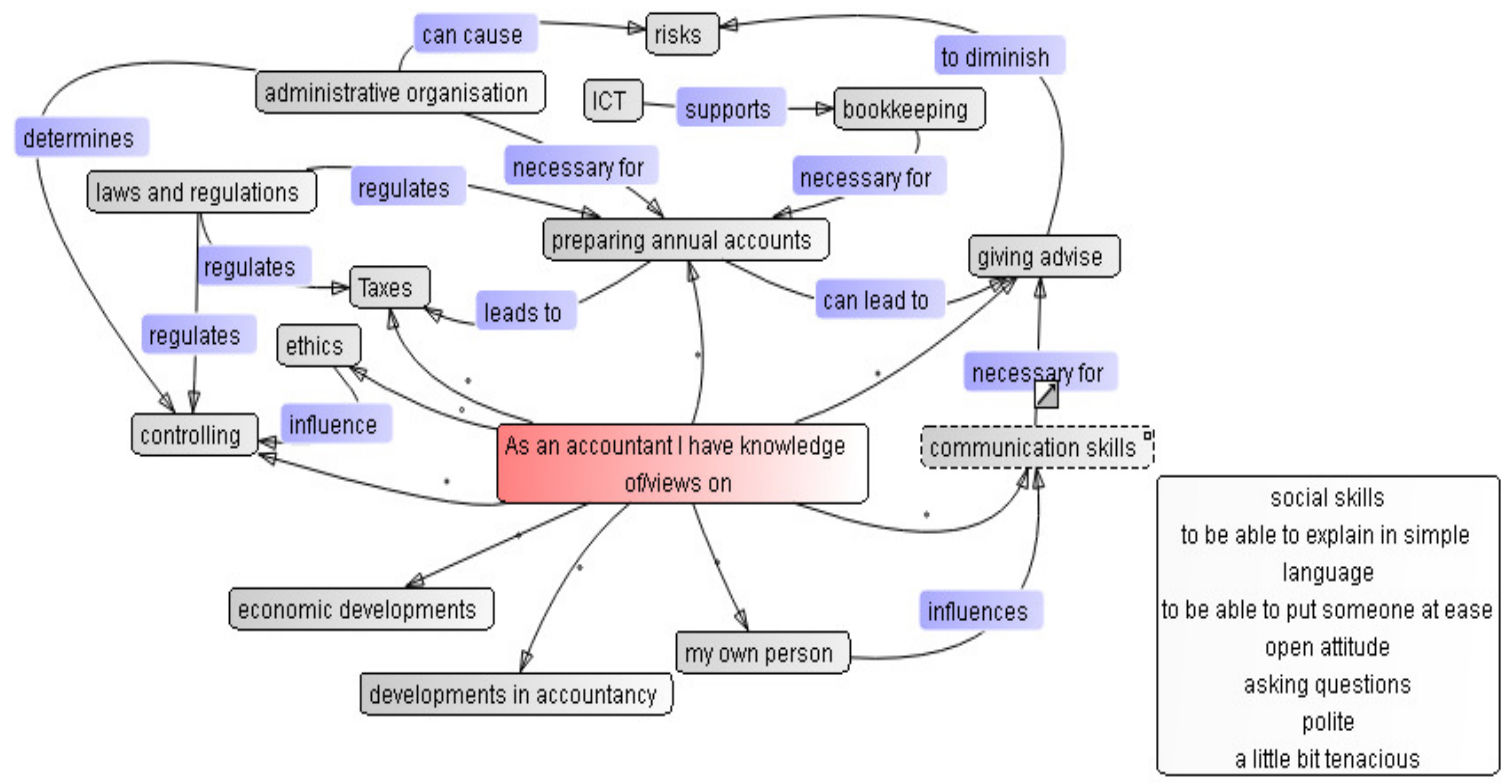

Figure 1. Pruned concept map of a (student) accountant, first measurement

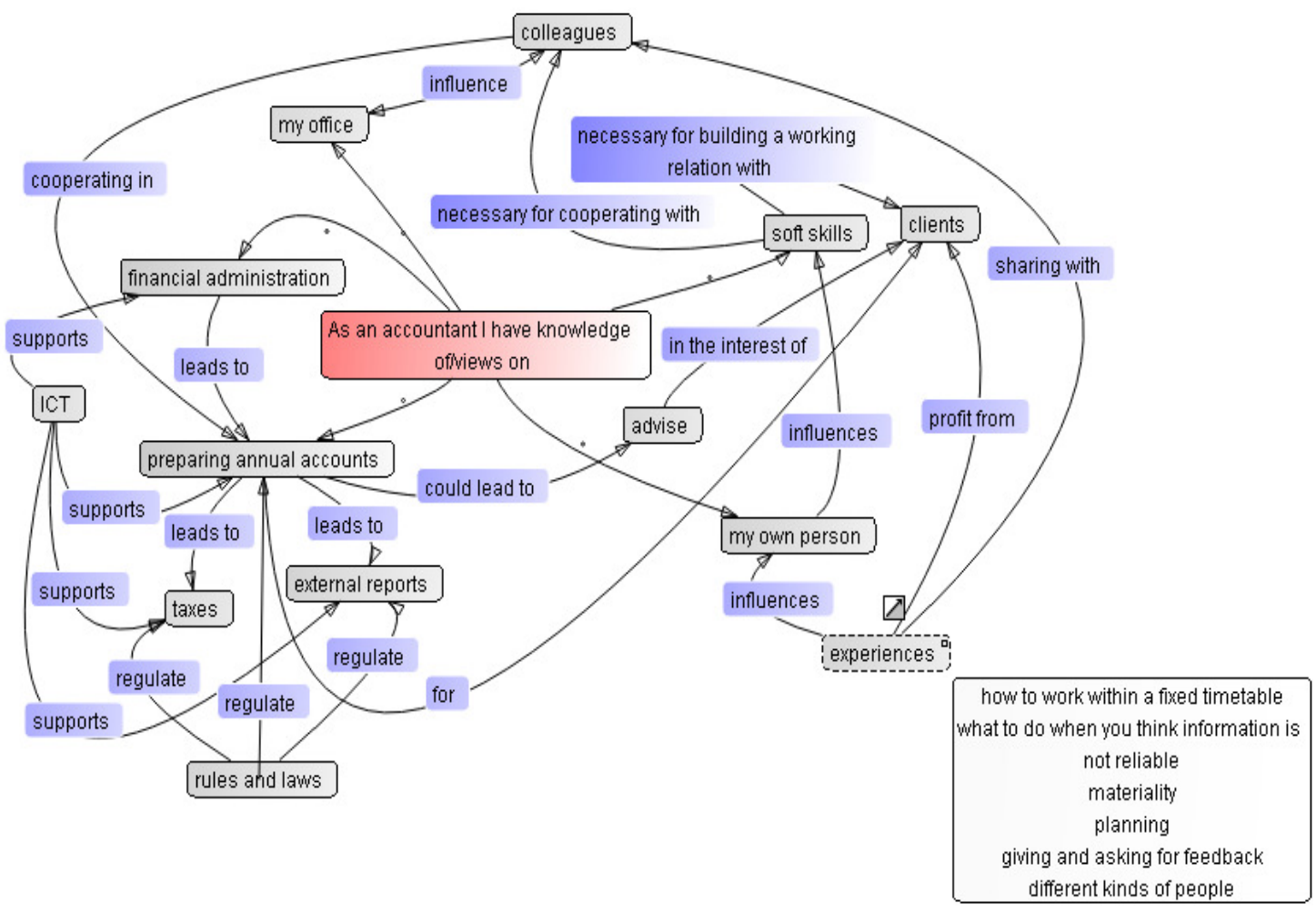

Figure 2. Pruned concept map of the same participant, third measurement 


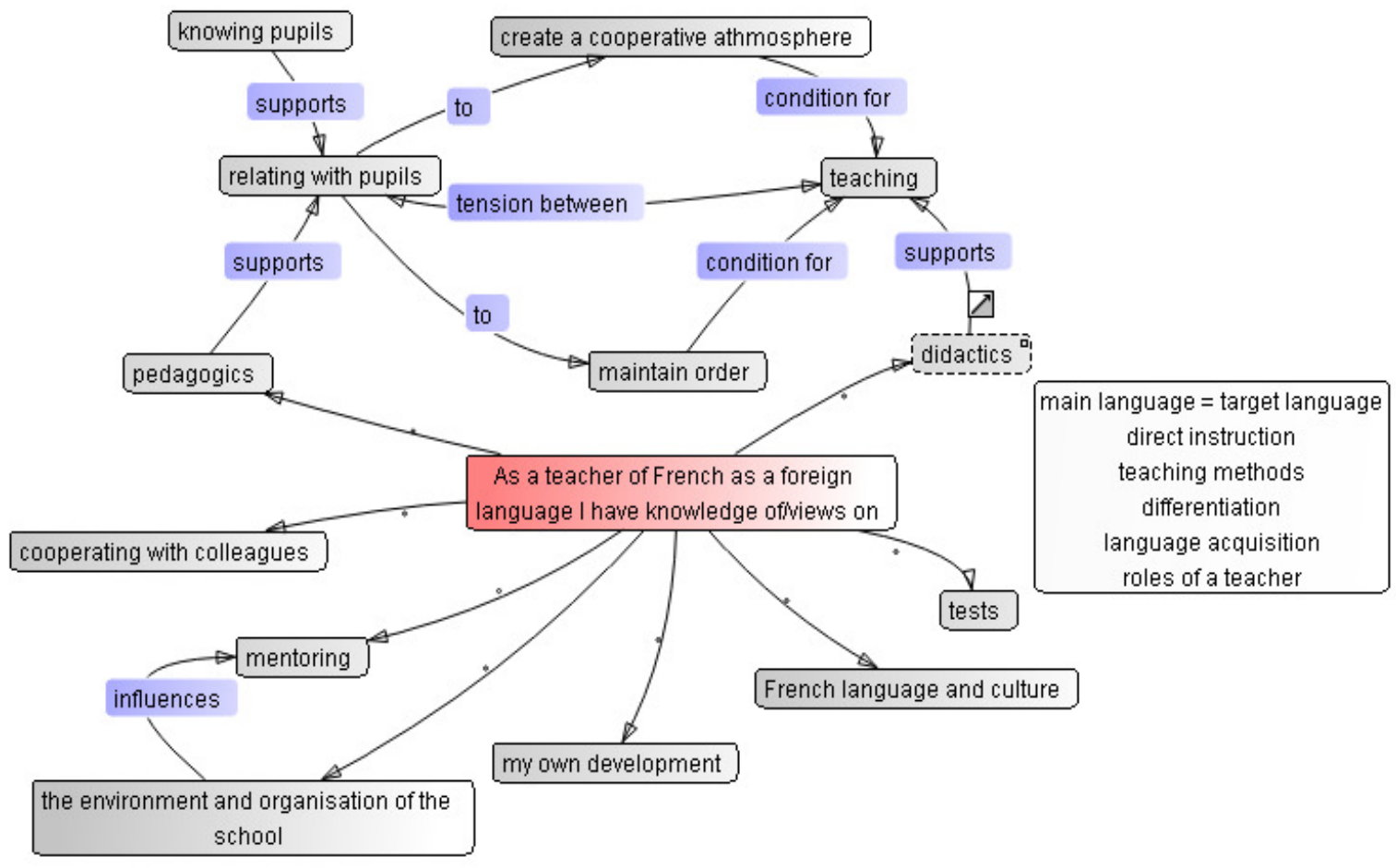

Figure 3. Pruned concept map of a (student) teacher, first measurement

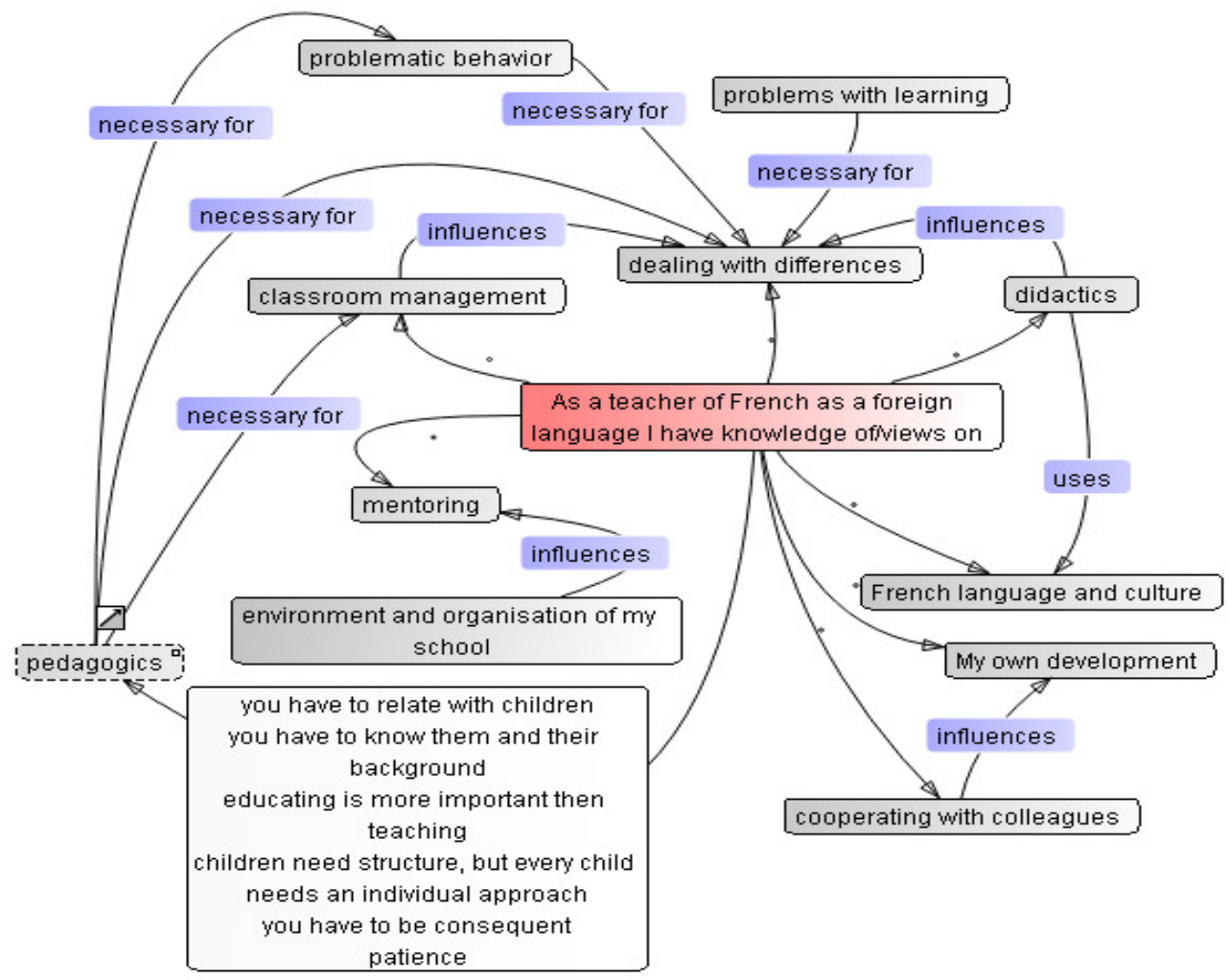

Figure 4. Pruned concept map of the same participant, third measurement 
Table 4. Numbers of primary concepts

\begin{tabular}{|c|c|c|c|c|}
\hline Measurement & Order of concepts & Origin & Accountants & Teachers \\
\hline First & Primary & & 63 & 67 \\
\hline \multirow{4}{*}{ Second } & \multirow{3}{*}{ Primary } & $\begin{array}{l}\text { (a) Primary in } \\
\text { first measurement }\end{array}$ & 50 & 42 \\
\hline & & $\begin{array}{l}\text { (b) Of lower order in } \\
\text { first measurement }\end{array}$ & 2 & 2 \\
\hline & & (c) New & 18 & 13 \\
\hline & Of lower order & $\begin{array}{l}\text { (d) Primary in } \\
\text { first measurement }\end{array}$ & 8 & 11 \\
\hline \multirow{4}{*}{ Third } & \multirow{3}{*}{ Primary } & $\begin{array}{c}\text { (a) Primary in } \\
\text { second measurement }\end{array}$ & 55 & 41 \\
\hline & & $\begin{array}{l}\text { (b) Of lower order in } \\
\text { second measurement }\end{array}$ & 2 & 3 \\
\hline & & (c) New & 7 & 10 \\
\hline & Of lower order & $\begin{array}{c}\text { (d) Primary in } \\
\text { second measurement }\end{array}$ & 8 & 10 \\
\hline
\end{tabular}

Characteristic new primary concepts appearing in the second or third

measurement of the accountants were: "knowledge of one's office", "cooperation with colleagues and with clients". "Advising clients" appeared in two maps as a primary concept and disappeared from three maps. In four accountants' maps the concept "controlling" disappeared. In six maps "bookkeeping" developed from a primary concept into a concept of lower order or disappeared. Characteristic new teachers' concepts from the second or third measurement were: "knowledge of one's own school" (e.g., cooperation with colleagues, culture of the school, importance of a healthy working climate), "parents", "the environment of the school" and "mentoring". "Differentiation" was a characteristic concept that disappeared from a number of teachers' concept maps (and sometimes reappeared again in the following). In two cases "subject knowledge" (e.g., knowledge of the foreign language) developed from a primary concept into a concept of lower order. Besides changes in the order of concepts and the (dis)appearance of concepts no other signs of changing opinions were found. In the interviews following the construction of the concept maps 
the order changes and (dis)appearances of concepts were discussed. This led to explanations such as "In school I have learned that this concept was important, but I have experienced that other concepts are more important" and "This concept has disappeared from my map because I do not use it in every day practice”.

When asked about their development, all participants indicated that in their view both the period between the first and the second measurement and the period between the second and the third were periods in which there was strong professional development. The accountants gave as the main sources of their development new experiences with clients and cooperation with colleagues. The participating teachers did not mention the second source.

\section{Conclusion and Discussion}

Regarding the first two research questions analysis of the data leads to the conclusion that the PPT concept maps of both the junior accountants and the novice teachers became more complex in the 1.5 years studied. Increase of richness could only be established in case of the novice teachers.

The increase of complexity and richness are in accordance with the arguments given the theoretical background. The increase of richness can also be deduced from the data in Table 3, as the distribution of annotations over the six objects of knowledge is clearly more uniform in the third measurement as compared with the two former measurements. In particular the decrease in the technical-instrumental domain and the increase in the domain target group are noteworthy and in accordance with what is known about the development of novice teachers (Vonk, 1995). The same tendencies can be deduced from the accountancy data in Table 3, however analysis showed the differences not to be significant $(p=.066)$. A possible 
explanation for this might be that junior accountants often have desk functions at the beginning of their careers with limited contact with clients (Eraut, Steadman, Furner, Maillardet, \& Blackman, 2004; Jeacle, 2008). The results suggest that both complexity and richness might be important development indicators. However, there is probably an important difference between the two. After all, the definition of richness implies that the richer a PPT is the more suited it is to support practice. The reason for this is that richness measures if all important aspects of a profession are present to a sufficient extent in a PPT as well as if they are uniformly distributed over the PPT. The consequence is that if one PPT is less rich than another one, the owner of the first PPT has less knowledge of one ore more aspects of his/her profession then the owner of the latter. This conclusion cannot be drawn for complexity: for instance a very complex PPT could load working memory thereby preventing energetically, appropriate professional judgements (Sweller, 2006).

Regarding the third research question, significant changes were not found in the level of generality of the concepts maps in either of the two domains. Given the analysis in the theoretical section, the reasons for this are not clear. It could be that there were opposite tendencies: some primary concepts became more general due to the formation of larger knowledge units, while others became more particular due to new individual experiences. Some examples of both developments were found such as in the teaching domain: "maintaining order" and "teaching methods" developing into "classroom management", and "knowledge of pupils" into "supporting pupils with learning problems". The first development might be interpreted as a sign that a scheme, "classroom management", has been formed in which already existing schemata, "maintaining order" and "teaching methods", were incorporated (Sweller, van Merrienboer, \& Paas, 1998). The second development might be caused by the 
fact that all attention was focused on helping pupils with learning problems, while other aspects of the support for pupils were automated or were paid less attention. If these interpretations are correct, they can be considered as indications that the level of generality of concepts in a PPT concept map is a relevant indicator of professional development. However, it is also possible that that there was no other reason for the changes in the labels of concepts than accident: a constructor has to choose labels while drawing a concept map.

Regarding the fourth research question the data from Table 4 show (dis)appearance of substantial numbers of concepts as well as changes in order. For instance (only) $63 \%$ of the teachers' concepts of the first concept maps appeared (whether or not generalised) in the second maps (42/67), and $40 \%$ of the primary concepts in the teachers' first maps became of a lower order in the second ones (13) or disappeared $(14=67-42-11)$. The percentages derived from the accountants' data are of a similar order of magnitude. The given explanations in the interviews refer to working conditions and experiences in practice as the cause for these changes (Vonk, 1995).

Order changes and the disappearance of concepts might be interpreted as an indication that certain subjects which are important 'in theory', are less important in practice. However, this interpretation is debatable, as research indicates that professional concepts which fade into the background in the beginning of a professional career, could become important after a certain degree of professional ripening has taken place (Messner \& Reusser, 2000).

Combining the results on all four research questions, the conclusion can be drawn that there has been substantial PPT development both in the accountant group and in the teacher group regarding complexity, richness (only for the teachers) and 
content. Although PPT development seems to be slow, the duration of the study and the chosen period allowed development to be measured. Moreover, PPT development seems to be in accordance with conjectures from expertise development. Both conclusions suggest that PPT development is an important aspect of expertise development and the concept map method is suited to elicit it. This means that concept maps could be used as a counseling instrument in the induction period (Helms-Lozentz \& Maulana, 2015). These claims need to be tempered as they were only made in two domains. More measurements in different domains have to taken. Moreover, different and more precise instruments have to be applied to get a more complete picture of PPT development and its relation with expertise development (Kagan, 1990; Vaatstra, 1996; van de Wiel, 1997). Finally, constructing concept maps is not a 'natural ability' leading to unique representations (Edmonson, 2000). This means that a part of the observed changes in concept maps could be caused by accidental factors, which have nothing to do with changes in PPTs. This is another reason for more measurements. 


\section{References}

Baartman, L. K. J., \& De Bruijn, E. (2011). Integrating knowledge, skills and attitudes: conceptualising learning processes towards vocational competence. Educational Research Review, 6, 125-134.

Bandura, A. (1991). Social cognitive theory of self-regulation. Organizational Behavior and Human Decision Processes. 50(2), 248-287.

Bjork, R. A. (2011). On the symbiosis of remembering, forgetting and learning. In A. S. Benjamin (Ed.), Successful remembering and successful forgetting: a festschrift in honour of Robert A. Bjork (pp. 1-22). New York, NY: Psychology Press.

Buitink, J. (1998). In-functie opleiden en in-functie leren van aanstaande leraren (Dissertation). Groningen: Rijksuniversiteit Groningen.

Chan, C. C. A., Monroe, G. S., Ng, J., \& Tan, R. C. W. (2008). Effects of employee support on junior accountants' job attitudes and intention to quit. Australian Accounting Review, 18, 149-162.

Chi, M. T. H., Feltovich, P. J., \& Glaser, R. (1981). Categorization and representation of physics problems by experts and novices. Cognitive Science, 5, 121-152.

Clarce, D., \& Hollingsworth, H. (2002). Elaborating a model of teacher professional growth. Teaching and Teacher Education, 18, 947-967.

Dalton, G. W., Thompson, P. H., \& Price, R. L. (1977). The four stages of professional careers-a new look at performance by professionals. Organizational Dynamics, 6(1), 19-42.

de Bruijn, E., \& Nieuwenhuis, L. F. M. (1994). Education between profession and market: the development of professional training. In W.J. Nijhof \& J. N. 
Streumer (Eds.), Flexibility in training and vocational education (pp. 109-131). Utrecht: Lemma.

de Groot, A. D. (1965). Thought and choice in chess. The Hague: Mouton.

Edmonson, K. M. (2000). Assessing science understanding through concept maps. In J. J. Mintzes, J. H. Wandersee, \& J. D. Novak (Eds.). Assessing science understanding; a human constructivist view (pp. 15-40). Burlington, MA: Elsevier Academic Press.

Eraut, M. (2009). Transfer of knowledge between education and workplace settings. In H. Daniels, H. Lauder, \& J. Porter (Eds.), Knowledge, values and educational policy; a critical perspective (pp. 1-17). New York, NY: Routledge.

Eraut, M., Steadman, S., Furner, J., Maillardet, F., Miller, C., Ali, A., \& Blackman, C. 2004, April). Learning in the professional workplace: relationships between learning factors ans contextual factors. Paper presented at the AERA 2994 Conference, San Diego, CA. Abstract retrieved from http://www.sussex.ac.uk/education/1-4-34-4.html.

Gartmeier, M., Bauer, J., Gruber, H., \& Heid, H. (2008). Negative knowledge: understanding professional learning and expertise. Vocations and Learning, 1(2), 87-103.

Goldstein, I., \& Papert, S. (1977). Artificial intelligence, language, and the study of knowledge. Cognitive science, 1(1), 84-123.

Goswwami, U. (2008). Cognitive development: the learning brain. Hove: Psychology Press.

Gracia, L. (2010). Accounting students' expectations and transition experiences of supervised work experience. Accounting Education, 19(1-2), 51-64. 
Helms-Lorentz, M., \& Maulana, R. (2015). Influencing the psychological well-being of beginning teachers across three years of teaching: self-efficacy, stress causes, job tension and job discontent. Educational Psychology, doi:

10.1080/01443410.2015.1008403.

Ingvarson, L., Meiers, M., \& Beavis, A. (2005). Factors affecting the impact of professional development programs on teachers' knowledge, practice, student outcomes and efficacy. Retrieved from $\underline{\text { http://research.acer.edu.au/professional_dev/II. }}$

Jeacle, I. (2008). Beyond the boring grey: the construction of the colourful accountant. Critical Perspectives on Accounting, 19(8), 1296-1320.

Kagan, D. M. (1990). Ways of evaluating teacher cognition: interference concerning the goldilocks principle. Review of Educational Research, 60, 419-469.

Kavanagh, M. H., \& Drennan, L. (2008). What skills and attributes does an accounting graduate need? Evidence from student perceptions and employer expectations. Accounting and Finance, 48, 279-300.

Kereluik, K., Mishra, P., Fahnoe, C., \& Terry, L. (2013). What knowledge is of most worth: teacher knowledge for $21^{\text {st }}$ century learning. Journal of Digital Learning in Teacher Education, 28(4), 127-140.

Korthagen, F. A. J. (2001). Linking practice and theory: the pedagogy of realistic teacher education. Paper presented at the Annual Meeting of the American Educational Research Association, Seattle, WA.

Messner, H., \& Reusser, K. (2000). Die berufliche Entwicklung von Lehrpersonen als lebenslanger Prozess. Beiträge zur Lehrersbildung, 18(2), 157-171.

Moline, J. N. (1986). Professionals and professions: a philosophical examination of an ideal. Social Science \& Medicine, 22(5), 501-508. 
Piore, M.J. (2002). Thirty years later: internal labour markets, flexibility and the new economy. Journal of Management and Governance, 6(4), 271-279.

Schaap, H. (2011). Students' personal professional theories in vocational education: developing a knowledge base. (dissertation) Utrecht: Universiteit Utrecht.

Schaap, H., Baartman, L., \& de Bruijn, E. (2012). Students' learning processes during school-based learning and workplace learning in vocational education: a review. Vocations and Learning, 5, 99-117.

Schaap, H., de Bruijn, E., \& van der Schaaf, M. F. (2007, november). The reflective apprenticeship model: cooperative learning and the development of personal professional theories of students of senior secondary vocational education. Paper presented at the 17th conference on the sociology of education, The Hague.

Schaap, H., de Bruijn, E., van der Schaaf, M. F., Baartman, L. K. J., \& Kirschner, P. A. (2011). Explicating students' personal professional theories in competence based vocational education through multi-method triangulation. Scandinavion Journal of Educational Research, 55, 567-586.

Schaap, H., de Bruijn, E., van der Schaaf, M. F., \& Kirschner, P. A. (2009). Students' personal professional theories in competence-based vocational education: the construction of personal knowledge through internalisation and socialisation. Journal of Vocational Education and Training, 61, 481-494.

Schaap, H., van der Schaaf, M. F., \& de Bruijn, E. (2011) Development of students' personal professional theories in senior secondary education. Evaluation \& Research in Education, 24(2), 81-103.

Schmidt, H. G., \& Boshuizen, H. P. A. (1993). On acquiring expertise in medicine. Educational Psychology Review, 5, 205-221. 
Sweller, J. (2006). How the human cognitive system deals with complexity. In J. Elen \& R. E. Clark (Eds.), Handling complexity in learning environments. Theory and research (pp. 13-26). Amsterdam: Elsevier

Sweller, J., van Merrienboer, J. J. G., \& Paas, F. G. W. C. (1998). Cognitive architecture and instructional design. Educational Psychology review, 10(3), 251-296.

Vaatstra, H. F. (1996). Expertise in accountancy. (Dissertation) Maastricht: Universitaire Pers: Maastricht.

van de Wiel, M. W. J. (1997). Knowledge encapsulation: studies on the development of medical expertise. (Dissertation) Maastricht: Universiteit Maastricht. van den Bogaart, A. C. M., Bilderbeek, R., Schaap, H., Hummel H. M. F., \& Kirschner, P. A. A. (2016). Computer Supported Method to Reveal and Assess Personal Professional Theories in Vocational Education. Technology, Pedagogy and Education. Advance online publication.

Doi/org/10.1080/1475939X.2015.1129986.

van den Bogaart, A. C. M., Mazereeuw, M., Hummel, H.M. F., \& Kirschner, P. A. Comparing collective and personal professional theories of experienced practitioners. Manuscript submitted for publication (a).

van den Bogaart, A. C. M., Schaap, H., Hummel, H. M. F., \& Kirschner, P. A. Combining Concept Maps and Interviews to Produce Representations of Personal Professional Theories in Higher Vocational Education: Effects of Order and Vocational Domain. Manuscript submitted for publication (b). van der Heijden, B. I. J. M. (1998). The measurement and development of professional expertise throughout the career; A retrospective study among higher level Dutch professionals. (Dissertation) Enschede: Universiteit Twente. 
van Oers, B. (1998). From context to contextualisation. Learning and Instruction, $8(6), 473-488$.

Vonk, J. H. C. (1995). Conceptualising novice teachers' professional development: a base for supervisory interventions. Paper presented at the annual meeting of the American Educational Research Association, San Francisco, CA. 